\title{
Awareness of cardiovascular disease among rural women of Uttarakhand
}

\section{Janki Joshi and Nidhi Trivedi}

Received: 28.05.2019; Revised: 13.10.2019; Accepted: 27.10 .2019

See end of the paper for authors' affiliations Janki Joshi

Department of Home Science, Surajmal Agarwal Private Kanya

Mahavidyala, Kichha

(Uttarakhand) India

Email : janki.30121@gmail.com
ABSTRACT : The most common type of heart disease is called coronary artery disease. Coronary artery disease develops when the arteries narrow and become hard. The heart cannot receive all the blood it needs through the stiff narrow arteries. Symptoms include pressure and chest pain or squeezing in the chest which is also known as angina. Present study was conducted to assess the awareness of rural women regarding cardiovascular disease and to see the association between educational level of the respondents and their awareness level about cardiovascular disease. It was found that 77 per cent respondents had low level of awareness regarding cardiovascular disease followed by 15 per cent respondents had medium level of awareness, whereas only 12 per cent respondents has high level of /awareness of cardiovascular disease. To see the association between educational level of the respondents and their awareness level about cardiovascular disease Chi-square test was applied and the results were found to be significant at $p<0.05$, indicating that educational level of respondents affect their awareness of Cardiovascular Disease.

KEY WORDS: Cardiovascular disease, Risk factor, Dietary modification, Lifestyle modification

- HOW TO CITE THIS PAPER : Janki, Joshi and Trivedi, Nidhi (2019). Awareness of cardiovascular disease among rural women of Uttarakhand. Asian J. Home Sci., 14 (2) : 325-328, DOI: 10.15740/HAS/ AJHS/14.2/325-328. Copyright@ 2019: Hind Agri-Horticultural Society. 